\title{
Theoretical studies on proton transfer reaction of 3(5)-substituted pyrazoles
}

\author{
ALIREZA NAJAFI CHERMAHINI ${ }^{\mathrm{a}, *}$ and ABBAS TEIMOURI ${ }^{\mathrm{b}}$ \\ ${ }^{a}$ Department of Chemistry, Isfahan University of Technology, 8415483111 Isfahan, Iran \\ ${ }^{\mathrm{b}}$ Chemistry Department, Payame Noor University, 19395-4697, Tehran, Islamic Republic of Iran \\ e-mail: anajafi@cc.iut.ac.ir; najafy@gmail.com
}

MS received 28 July 2013; revised 28 September 2013; accepted 10 November 2013

\begin{abstract}
The inter and intra molecular proton transfer reactions of a series of pyrazole derivatives have been studied by using density functional theory (DFT) and MP2 methods implementing 6-311++G(d,p) atomic basis set. The substituents have been selected to cover a wide range of electronic effects. Proton transfer process was studied for mechanisms including single proton transfer, double proton transfer and proton transfer assisted by a water or ammonia molecule. The results showed single proton transfer reactions for interconversion pyrazole derivatives need highest activation energies in the range of $45.7-51.59$ and $49.4-53.96 \mathrm{kcal} / \mathrm{mol}$ at B3LYP and MP2 levels, respectively. It was found that for the 3-substituted pyrazoles, electron withdrawing groups form stronger dimers but in the 5-substituted tautomers electron donating groups form stronger hydrogen bond. The double proton transfer reactions between dimers were studied and transition states calculated. The ranges of activation energies were found to be $17.51-19.36$ and $17.02-17.80 \mathrm{kcal} / \mathrm{mol}$ for the $\mathbf{C} \rightarrow \mathbf{E}$ and $\mathbf{D} \rightarrow \mathbf{D}$ reactions respectively. In addition, the activation energies for the proton transfer reaction assisted by water or ammonia molecules were found to be in the range of $26.62-31.78$ and $17.25-22.46 \mathrm{kcal} / \mathrm{mol}$, respectively, calculated at MP2/6-311++G(d,p) level of theory.
\end{abstract}

Keywords. Pyrazoles; substituent effect; solvent assisted proton transfer; double proton transfer.

\section{Introduction}

Pyrazole is a five-membered heterocyclic compound containing two nitrogen atoms. ${ }^{1}$ The growth of pyrazole chemistry over the last 25 years has been significant, mainly as a result of the roles played by its derivatives in coordination chemistry as ligands ${ }^{2}$ and in medicinal chemistry. For example, amino-pyrazole derivatives were found to be potentially useful in preventing brain-protein aggregation which is the first phase in the development of Alzheimer's disease. ${ }^{3}$ Other examples are Sildenafil, ${ }^{4}$ an inhibitor of 5-phosphodiesterase, used for the treatment of erectile dysfunction, Celebrex, an inhibitor of cyclooxygenase-2 (COX-2), used as potent antiinflammatory, ${ }^{5}$ and Acomplia, antagonist of the CB-1 cannabinoid receptor, used for the treatment of obesity. ${ }^{6}$ In addition, pyrazole derivatives have been used as cardiovascular and oncologytic agents. ${ }^{7,8}$ Due to the small size of pyrazole and rigidity of its fivemembered ring, it has been used as a model molecule for the evaluation of the accuracy of different computational methods. ${ }^{9}{ }^{10}$ Pyrazole derivatives substituted at 3position can exist in two tautomeric forms (scheme 1)

*For correspondence and its annular tautomerism has been thoroughly studied both experimentally ${ }^{10}$ and theoretically. ${ }^{11}$

$\mathrm{N}$-unsubstituted pyrazoles can have $\mathrm{N}-\mathrm{H} \cdots \mathrm{N}$ hydrogen bonds present in their crystals, which can lead to at least six motifs such as monomers, dimers, trimers, tetramers, hexamers, and catemers. Hydrogenbonding motifs for pyrazoles have been examined in the Cambridge Structural Database (CSD). ${ }^{12}$ It was reported that in the gas phase, both pyrazole and 3,5-dimethylpyrazole exist in an equilibrium between monomer, dimer, and trimer. However in solution, the equilibrium between monomer and trimer dominated and no band which could be attributed to dimers were detected. ${ }^{13,14}$ Moreover, Castaneda et al. studied vibrational spectra and structure of hydrogen bonded complexes formed by pyrazole and 3,5-dimethylpyrazole (DMP) and examined complexation with some proton donating compounds. ${ }^{15}$ The double proton transfer reactions between some substituted pyrazoles and guanidine molecule were studied by Schweiger and co-workers. ${ }^{16}$ It was shown that in contrast to typical reactions, two of the systems showed broad plateaus of almost constant energy along the minimum energy path (MEP) instead of the well localized transition state. In addition, Limbach and co-workers studied 


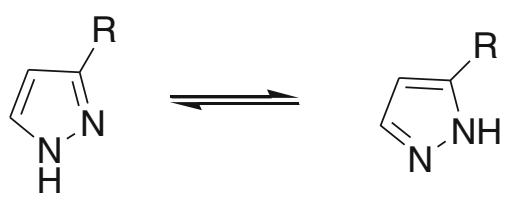

Scheme 1. Tautomeric forms of 3-substituted pyrazoles.

the structure of solid pyrazole-4-carboxylic acid and found that the compound forms quasi-linear ribbons in which the molecules are linked by cyclic hydrogen bonds between pyrazole and carboxylic acid groups with disordered hydrogen-bonded protons. ${ }^{17}$ Recently, Ochsenfeld et al. have presented an elegant study about the insertion of pyrazole unit in a peptide which associates intermolecularly, giving rise to nanorosette-type structures in water. ${ }^{18}$ In another work, Garcia and co-workers studied tautomeric behaviour and aggregation of a series of 3(5)-phenyl pyrazoles in the solid and solution phase. ${ }^{19}$ Recently, we have reported the results of our study on the proton transfer reaction in the 4-substituted pyrazoles. ${ }^{20}$ In continuation with our program to investigate the effect of substituents on the properties of heterocycles ${ }^{21-24}$, here, we report the results of our investigation on the proton transfer reaction of 3(5) pyrazole derivatives.

\section{Computational procedures}

DFT and MP2 calculations were performed using GAUSSIAN 03 package. ${ }^{25}$ The density functional theory was used with the Becke3-Lee-Yang-Parr (B3LYP) exchange-correlation with the conventional $6-311++G(d, p)$ basis sets. ${ }^{26,27}$ According to recent reports, hybrid functionals can provide better description for the systems with hydrogen bonds. ${ }^{28,29}$ The nature of all optimized structures was determined using harmonic frequency analysis as true minima with no imaginary frequencies or transition states with only one imaginary frequency. The hydrogen bonding energy of the studied dimer was corrected both with basis set superposition error (BSSE) and zero-point vibrational energies (ZPVE) ${ }^{30}$ In our calculation particular emphasizes delivered on the $6-311++\mathrm{G}(\mathrm{d}, \mathrm{p})$ basis set because this basis set is of triple-zeta quality ${ }^{31,32}$ for valence electrons with diffuse functions, which are useful in calculations for anions and structures with lonepair electrons. ${ }^{33,34}$ Comparisons of results of different basis sets reflect that most crucial achievement of $\mathrm{H}$ bond energy comes with this basis set. This observation reasonably complies with other reports. ${ }^{35}$ The geometry of the proton transfer reactions was determined using QST2 method at the MP2/6-311++G(d,p) level of theory. The structure of transition states between each pair of tautomers in the monomers, dimers and proton transfer reactions assisted by solvent molecules, were optimized by applying Schlegel's Synchronous Transitguided Quasi-Newton (QST2) method started from the fully optimized structure of one tautomer and finished on the fully optimized structure of another tautomer. This route is requested by the keyword Opt $=$ QST2 option. The TSs were verified with frequency calculations to ensure they were first order saddle points with only one imaginary frequency mode.

\section{Results and discussion}

The structures and arbitrary numbering of monomers and dimers of pyrazole derivatives that considered in the present study has shown in figures 1 and 2 . In the $\mathbf{C}$ and $\mathbf{E}$, dimers, the 3-R and 5-R derivatives form the dimer, respectively. In addition, the $\mathbf{D}$ dimers are formed from a 3-R monomer and a 5-R monomer. For the nitroso and carbaldehyde groups, different conformers may exist, we considered more stable ones.

\subsection{Proton transfer in monomers}

The results of calculated total energies and relative stabilities of tautomers of pyrazole derivatives that considered in the present study are shown in table 1.

The results indicate that for electron donating groups such as $\mathbf{N H}_{2}, \mathbf{C H}_{3}$, and $\mathbf{F}$ 3-substituted pyrazoles (B forms) are more stable but for electron withdrawing groups 5-substituted ones (A forms) are more stable. For example, based on B3LYP/6-311++G(d,p) calculations, 3-fluoro and 3-amino pyrazole are 3.62 and $2.61 \mathrm{kcal} / \mathrm{mol}$ more stable than their corresponding 5-flouro and 5-amino pyrazoles, respectively.

The proton transfer reaction of pyrazole derivatives studied and activation energies were calculated and presented in table 1 . The obtained results show that activation energies for proton transfer reaction varies in the range of $45.7-51.59$ and $49.4-53.96 \mathrm{kcal} / \mathrm{mol}$ at MP2 and B3LYP levels, respectively. Analysis of the results indicates proton migration is easier in pyrazoles with electron donating groups. For example, based on MP2 calculations the activation energy of the proton transfer process for the 3-hydroxy and 3-amino pyrazole was found to be 47.52 and $47.34 \mathrm{kcal} / \mathrm{mol}$, respectively. On the other hand, for the 3-nitro and 3-nitroso pyrazole that electron withdrawing groups attached to the ring, the activation energy of proton transfer reaction found 50.69 and $51.59 \mathrm{kcal} / \mathrm{mol}$, respectively. We found a good correlation between substituent constants 


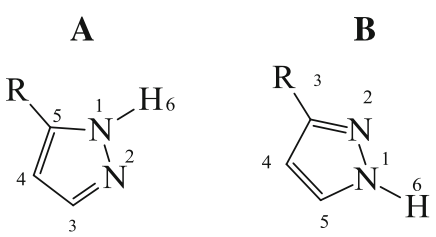

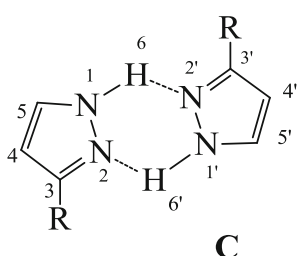

C

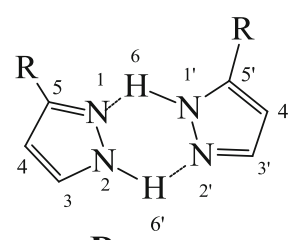

D<smiles></smiles>

$\mathbf{E}$

$\mathrm{R}=\mathrm{H}, \mathrm{OH}, \mathrm{NH}_{2}, \mathrm{Cl}, \mathrm{F}, \mathrm{CH}_{3}, \mathrm{NO}_{2}, \mathrm{CHO}, \mathrm{NO}$

Figure 1. Structures and arbitrary numbering of pyrazole monomers $(\mathbf{A}, \mathbf{B})$ and dimers $(\mathbf{D}, \mathbf{C}, \mathbf{E})$ which have been considered in this work.

$\left(\sigma_{I}\right)$ and activation energies with a correlation coefficients 0.947 calculated at MP2/6-311++G(d,p) level of theory.

\subsection{Hydrogen bonding strength in dimmers}

Interaction energies were calculated for the 3- and 5substituted pyrazole-pyrazole aggregates by taking the energy differences between the fragments and the complexes. The results of calculations are compiled in table 2. Based on our calculations the following results obtained. Complexation of 3-substituted pyrazoles lead to the $\mathbf{C}$ isomers, the stabilization energies calculated at MP2 and B3LYP methods using 6-311++G(d,p) basis function in the table 2 indicate that the order of stability is $\mathbf{C H O}>\mathbf{N O}>\mathbf{N O}_{2}>\mathbf{C l}>\mathbf{O H}>\mathbf{F}>\mathbf{H}>\mathrm{CH}_{3}>$ $\mathrm{NH}_{2}$ and $\mathrm{CHO}>\mathrm{NO}>\mathrm{NO}_{2}>\mathrm{Cl}>\mathrm{F}>\mathrm{CH}_{3}>\mathrm{H}>\mathrm{OH}>$ $\mathbf{N H}_{2}$ at the DFT and MP2 levels, respectively. These data reveals that electron withdrawing groups form

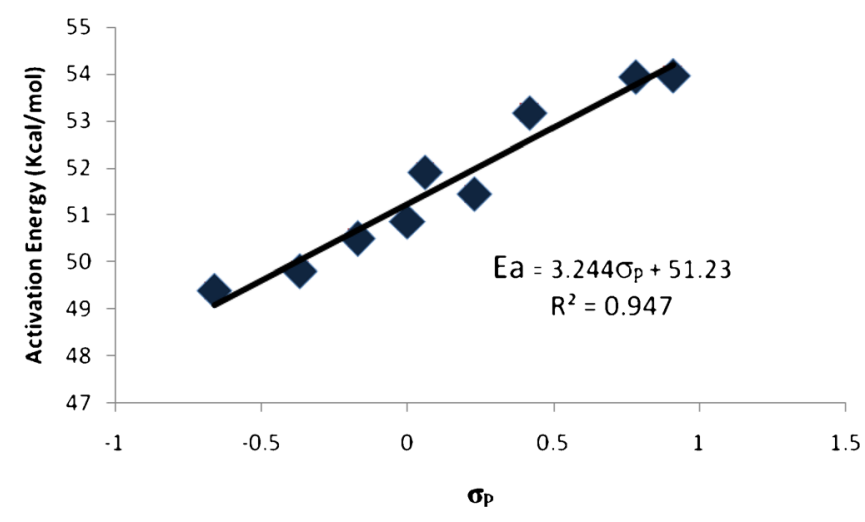

Figure 2. Correlation between substituent constants and activation energies of proton transfer reaction in the pyrazole monomers. stronger hydrogen bonds. The most stable isomer has -15.54 and $-21.75 \mathrm{kcal} / \mathrm{mol}$ interaction energy calculated at DFT and MP2 levels using 6-311++G(d,p) basis set. For the electron donating groups such as $\mathrm{NH}_{2}$ and $\mathrm{CH}_{3}$ the interaction energies were found to be -11.29 and $-11.89 \mathrm{kcal} / \mathrm{mol}$ at DFT level and -14.68 and $-15.56 \mathrm{kcal} / \mathrm{mol}$ at MP2 level, respectively. With application of ZPE and BSSE corrections, the stabilization energies of the complexes decrease about $1.62-2.05$ and $3.04-3.33 \mathrm{kcal} / \mathrm{mol}$ using DFT and MP2 methods, respectively. However, the corrections with ZPE and BSSE have no significant influence on the stability order of dimers. The calculated interaction energies for the 5-substituted pyrazole dimers ( $\mathbf{E}$ dimers) presented in the table 2. Based on DFT results the order of stability was found to be $\mathbf{N H}_{2}>\mathbf{F}>\mathbf{C H}_{3}>$ $\mathrm{Cl}>\mathrm{NO}_{2}>\mathrm{CHO}>\mathrm{NO}>\mathrm{OH}$ and $\mathrm{Cl}>\mathrm{CH}_{3}>\mathrm{F}>\mathrm{NO}_{2}>$ $\mathbf{N H}_{2}>\mathbf{N O}>\mathbf{C H O}>\mathbf{O H}$ calculated using DFT and MP2 methods, respectively. As it can be seen from table 2, the hydrogen bond strengths are significantly lower than homo-dimers between 3- and 5-substituted dimers of pyrazole derivatives. For more evaluation of hydrogen bond formation we studied the dimer formation between 3- and 5-substituted pyrazole derivatives (D dimers). Based on DFT results, the order of stability found to be $\mathbf{O H}>\mathbf{F}>\mathbf{C l}>\mathbf{C H}_{3}>\mathbf{N H}_{2}>\mathbf{N O}>$ $\mathrm{NO}_{2}>\mathrm{CHO}$ indicates that electron donating groups form more effective hydrogen bonds. However, noticeably the order of hydrogen bonding based on MP2 results was found completely different with DFT results and found to be $\mathbf{N O}>\mathbf{C l}>\mathbf{C H O}>\mathbf{C H}_{3}>\mathbf{O H}>\mathbf{F}>\mathbf{N O}_{2}>$ $\mathbf{N H}_{2}$. In addition, with application of ZPE and BSSE corrections the order of stability calculated by MP2 method changed to $\mathbf{N O}>\mathbf{C H O}>\mathbf{C l}>\mathbf{O H}>\mathbf{F}>\mathbf{C H}_{3}>$ $\mathbf{N O}_{2}>\mathbf{N H}_{2}$. The calculated data for the substituted pyrazoles are comparable with previously reported 
Table 1. Calculated relative stabilities of two tautomers of pyrazole derivatives and activation energies of proton transfer reactions at MP2 and DFT levels.

\begin{tabular}{llcccccc}
\hline & \multicolumn{2}{c}{ MP2/6-311++G(d,p) } & & \multicolumn{2}{c}{ B3LYP/6-311++G(d,p) } \\
\cline { 2 - 4 } & $\mathbf{A}$ & $\mathbf{B}$ & $\mathrm{E}_{\mathrm{a}}$ & & $\mathbf{A}$ & \multicolumn{1}{c}{$\mathbf{B}$} & $\mathrm{E}_{\mathrm{a}}$ \\
\hline $\mathbf{H}$ & 0 & - & 48.26 & & 0 & - & 50.87 \\
$\mathbf{N H}_{2}$ & 0 & $-1.56^{\mathrm{b}}$ & 47.34 & & 0 & -2.61 & 49.40 \\
$\mathbf{O H}$ & 0 & -0.56 & 47.53 & & 0 & -0.37 & 49.80 \\
$\mathbf{C l}$ & 0 & -1.36 & 47.31 & & 0 & -1.58 & 51.46 \\
$\mathbf{F}$ & 0 & -3.62 & 45.79 & & 0 & -3.62 & 51.91 \\
$\mathbf{C H}_{3}$ & 0 & -0.25 & 47.50 & & 0 & -0.26 & 50.49 \\
$\mathbf{N O}_{2}$ & 0 & 1.64 & 50.62 & & 0 & 0.23 & 53.95 \\
$\mathbf{C H O}$ & 0 & 4.00 & 50.84 & & 0 & 2.16 & 53.16 \\
$\mathbf{N O}$ & 0 & 2.69 & 51.59 & & 0 & 0.43 & 53.96 \\
\hline
\end{tabular}

${ }^{\text {a }}$ Relative stabilities in $\mathrm{kcal} / \mathrm{mol}$

values for the hydrogen bond strength of heterocyclic compounds. For example, the strength of hydrogen bonds for the various type of tetrazole derivatives found in the range of $8.19-13.55 \mathrm{kcal} / \mathrm{mol}$ calculated at
B3LYP/6-311++G(d,p) level of theory. ${ }^{28}$ In addition, for the 4-substituted pyrazoles the range of hydrogen bond strength was found to be $14.9-15.4 \mathrm{kcal} / \mathrm{mol}$ calculated at MP2/6-311++G(d,p) level of theory. ${ }^{20}$

Table 2. Calculated interaction energies for the 3- and 5-substituted doubly hydrogen bonded pyrazoles using 6$311++\mathrm{G}(\mathrm{d}, \mathrm{p})$ basis function at DFT and MP2 level.

\begin{tabular}{|c|c|c|c|c|c|c|c|c|}
\hline & $\mathbf{E}_{i n t}$ & $\mathrm{E}_{\text {int }(Z P V E)}$ & BSSE & $\mathrm{E}_{\text {int }(\text { Corr })}$ & $\mathrm{E}_{i n t}$ & & BSSE & $\mathrm{E}_{\text {int }(\text { Corr })}$ \\
\hline & & B3LYP/6-3 & $+\mathrm{G}(\mathrm{d}, \mathrm{p})$ & & \multicolumn{4}{|c|}{ MP2/6-311++G(d,p) } \\
\hline \multicolumn{9}{|c|}{ C dimers } \\
\hline H & $-12.21^{\mathrm{a}}$ & -10.98 & 0.48 & -10.50 & -15.42 & -14.29 & 2.0 & -12.29 \\
\hline $\mathbf{N H}_{2}$ & -11.29 & -9.80 & 0.56 & -9.24 & -14.68 & -13.60 & 2.25 & -11.35 \\
\hline $\mathrm{OH}$ & -12.50 & -11.03 & 0.57 & -10.46 & -15.16 & -14.30 & 2.17 & -12.13 \\
\hline $\mathrm{Cl}$ & -12.73 & -11.67 & 0.73 & -10.94 & -16.69 & -16.13 & 2.69 & -13.44 \\
\hline $\mathbf{F}$ & -12.46 & -11.28 & 0.63 & -10.65 & -15.67 & -14.73 & 2.22 & -12.51 \\
\hline $\mathrm{CH}_{3}$ & -11.89 & -10.78 & 0.55 & -10.23 & -15.56 & -14.86 & 2.38 & -12.48 \\
\hline $\mathrm{NO}_{2}$ & -14.37 & -13.41 & 0.66 & -12.75 & -18.59 & -18.0 & 2.48 & -15.52 \\
\hline CHO & -15.54 & -14.38 & 0.63 & -13.75 & -21.75 & -20.95 & 2.43 & -18.52 \\
\hline NO & -14.90 & -13.75 & 0.68 & -13.07 & -21.06 & -20.13 & 2.34 & -17.79 \\
\hline \multicolumn{9}{|c|}{ D dimmers } \\
\hline $\mathbf{N H}_{2}$ & -12.09 & -10.93 & 0.55 & -10.38 & -14.48 & -13.68 & 2.21 & -11.47 \\
\hline $\mathrm{OH}$ & -12.41 & -11.26 & 0.62 & -10.64 & -15.78 & -14.81 & 2.3 & -12.51 \\
\hline $\mathrm{Cl}$ & -12.20 & -11.16 & 0.73 & -10.43 & -16.24 & -15.41 & 2.74 & -12.67 \\
\hline $\mathbf{F}$ & -12.34 & -11.20 & 0.63 & -10.57 & -15.60 & -14.71 & 2.27 & -12.47 \\
\hline $\mathrm{CH}_{3}$ & -12.10 & -11.0 & 0.54 & -10.46 & -15.82 & -14.74 & 2.38 & -12.36 \\
\hline $\mathrm{NO}_{2}$ & -10.31 & -9.49 & 0.68 & -8.81 & -14.77 & -14.63 & 2.54 & -12.09 \\
\hline CHO & -8.63 & -7.80 & 0.61 & -7.19 & -16.10 & -15.40 & 2.47 & -12.93 \\
\hline NO & -10.83 & -9.91 & 0.63 & -9.28 & -16.43 & -15.69 & 2.33 & -13.36 \\
\hline \multicolumn{9}{|c|}{$\mathbf{E}$ dimers } \\
\hline $\mathbf{N H}_{2}$ & -12.98 & -11.88 & 0.56 & -11.32 & -13.92 & -13.51 & 2.20 & -11.31 \\
\hline OH & -9.13 & -8.45 & 0.61 & -6.84 & -11.92 & -11.86 & 2.30 & -9.56 \\
\hline $\mathrm{Cl}$ & -11.97 & -10.95 & 0.72 & -10.23 & -15.97 & -15.31 & 2.76 & -12.50 \\
\hline $\mathbf{F}$ & -12.57 & -11.43 & 0.63 & -10.80 & -15.08 & -14.95 & 2.31 & -12.64 \\
\hline $\mathrm{CH}_{3}$ & -12.39 & -11.24 & 0.53 & -10.71 & -15.69 & -14.78 & 2.26 & -12.52 \\
\hline $\mathbf{N O}_{2}$ & -9.8 & -9.1 & 0.68 & -8.31 & -14.43 & -14.06 & 2.52 & -11.54 \\
\hline CHO & -9.35 & -8.59 & 0.58 & -8.01 & -12.44 & -11.88 & 2.46 & -9.42 \\
\hline NO & -9.24 & -8.44 & 0.65 & -7.79 & -13.18 & -12.62 & 2.42 & -10.20 \\
\hline
\end{tabular}

${ }^{\mathrm{a} B i n d i n g}$ energies in $\mathrm{kcal} / \mathrm{mol}$ 
On the whole, one can conclude that for the 3substituted pyrazoles, more effective hydrogen bonds formed for the electron withdrawing groups, but for the 5-substituted ones electron donating groups formed stronger hydrogen bonds.

\subsection{Double proton transfer reaction}

The proton transfer reaction is a very important biochemical process, which may occur directly without any assistance of the solvent molecule or assisted by one or more solvent molecule..$^{29,35-38,40}$ A vast amount of research has been focusing on various types of proton transfers in ground states as well as in the excited states to explore the associated reaction mechanism. ${ }^{41-44}$ The activation energies $E a$ for direct proton transfer reaction of pyrazole derivatives are presented in table 3 . Two different double proton transfer reaction was studied: for the $\mathbf{C} \rightarrow \mathbf{E}$ reaction where $\mathbf{C}$ dimers convert to $\mathbf{E}$ ones and for the $\mathbf{D} \rightarrow \mathbf{D}$ reactions, the $\mathbf{D}$ dimers convert to themselves through double proton transfer process. From table 3, it is evident that the proton transfer process is characterized by moderate activation energies. For the $\mathbf{C} \rightarrow \mathbf{E}$ process the activation energies found in the range of $17.51-19.36 \mathrm{kcal} / \mathrm{mol}$, calculates at MP2/6-311++G(d,p) level of theory. For the parent pyrazole molecule, activation energy and zeropoint corrected activation energy found to be 17.99 and $13.07 \mathrm{kcal} / \mathrm{mol}$, respectively. Moreover, for the 3amino pyrazole the activation and corrected activation energies were found to be 17.72 and $12.33 \mathrm{kcal} / \mathrm{mol}$, respectively. However, for the pyrazole substituted by electron withdrawing groups such as nitroso and $\mathrm{CHO}$ conversion of $\mathbf{C}$ isomer to $\mathbf{E}$ one need 19.36 and $18.92 \mathrm{kcal} / \mathrm{mol}$, respectively.

For the $\mathbf{D} \rightarrow \mathbf{D}$ process the activation energies found in the range of $17.02-17.80 \mathrm{kcal} / \mathrm{mol}$. With inclusion of ZPE values the range of activation energies decreased to $11.56-12.87 \mathrm{kcal} / \mathrm{mol}$. As you can see, the most activation energy obtained for the pyrazole substituted with amino group by $17.80 \mathrm{kcal} / \mathrm{mol}$ value. One can compare these values obtained for the double proton, transfer reactions with intramolecular proton transfer the reactions of pyrazole monomers described in previous section. As it has been shown the activation energies observed for the double proton transfer reaction are considerably lower than those found for the intermolecular processes. For example, the intermolecular proton transfer reaction of conversion of 3-nitro pyrazole to 5-nitro pyrazole $(\mathbf{B} \rightarrow \mathbf{A})$ needs $50.62 \mathrm{kcal} / \mathrm{mol}$, however for this process through double proton transfer route $(\mathbf{C} \rightarrow \mathbf{E}$ reaction) where 5-nitro and 3-nitro pyrazoles form the dimer, the activation energy found to be $18.67 \mathrm{kcal} / \mathrm{mol}$. Similar results for other derivatives was observed (compare tables 1 and 3). The optimized structures of the transition states and some important geometrical parameters of proton transfer reactions of pyrazole dimers have been presented in figure 3 .

It is evident that value of the imaginary frequency is a measure of the curvature of the transition state region along the reaction coordinate. The calculated values of imaginary frequencies of double proton transfer reactions of pyrazole derivatives presented in table 3 . A close look to results indicates there is good correlation between activation energies and values of imaginary frequencies was observed. The values of imaginary frequencies that correlate with activation energies found in the range of -1231.6 to -1487.7 and -1245.4 to $-1489.5 \mathrm{~cm}^{-1}$, for the transition states of $\mathbf{C} \rightarrow \mathbf{E}$ and $\mathbf{D} \rightarrow \mathbf{D}$ reactions, respectively.

\subsection{Solvent assisted proton transfer reaction}

Protic solvents such as water, alcohols or ammonia that can be a strong hydrogen bond donor/acceptor can accept a proton from the donor site of the solute molecule or give another proton to the suitable sites of the solute. Solvent-assisted proton transfer mechanism studies have shown that the assistance of a water molecule significantly lowers the free energy barriers in proton-transfer-related reactions. ${ }^{20,45-47}$ In this case, an explicit interaction with a limited number of solvent

Table 3. Calculated activation energies, corrected activation energies and imaginary frequencies of proton transfer reaction in substituted pyrazole dimers at MP2/6-311++G(d,p) level of theory.

\begin{tabular}{llccccccccc}
\hline Reaction & & $\mathbf{H}$ & $\mathbf{N H}_{\mathbf{2}}$ & $\mathbf{O H}$ & $\mathbf{C l}$ & $\mathbf{F}$ & $\mathbf{C H}_{\mathbf{3}}$ & $\mathbf{N O}_{\mathbf{2}}$ & $\mathbf{C H O}$ & $\mathbf{N O}$ \\
\hline $\mathbf{C} \rightarrow \mathbf{E}$ & $\mathrm{Ea}$ & $17.99^{\mathrm{a}}$ & 17.72 & 17.51 & 18.86 & 17.58 & 17.80 & 18.62 & 18.92 & 19.36 \\
& $\mathrm{Ea}+\mathrm{ZPE}$ & 13.07 & 12.33 & 12.31 & 12.82 & 15.66 & 12.77 & 12.85 & 13.29 & 13.37 \\
& $v_{1}$ & -1487.7 & -1231.6 & -1387.3 & -1466.5 & -1476.1 & -1414.8 & -1459.5 & -1466.4 & -1470.3 \\
$\mathbf{D} \rightarrow \mathbf{D}$ & & & & & & & & & & \\
& $\mathrm{Ea}$ & - & 17.80 & 17.73 & 17.02 & 17.60 & 17.70 & 17.20 & 17.31 & 17.56 \\
& $\mathrm{Ea}+\mathrm{ZPE}$ & - & 12.87 & 11.91 & 11.56 & 11.97 & 12.34 & 11.80 & 11.88 & 11.89 \\
& $v_{1}$ & - & -1245.4 & -1474.2 & -1467.9 & -1489.5 & -1431.3 & -1463.6 & -1439.7 & -1477.3 \\
\hline
\end{tabular}

\footnotetext{
${ }^{\mathrm{a}}$ Activation energies in $\mathrm{kcal} / \mathrm{mol}$.
} 

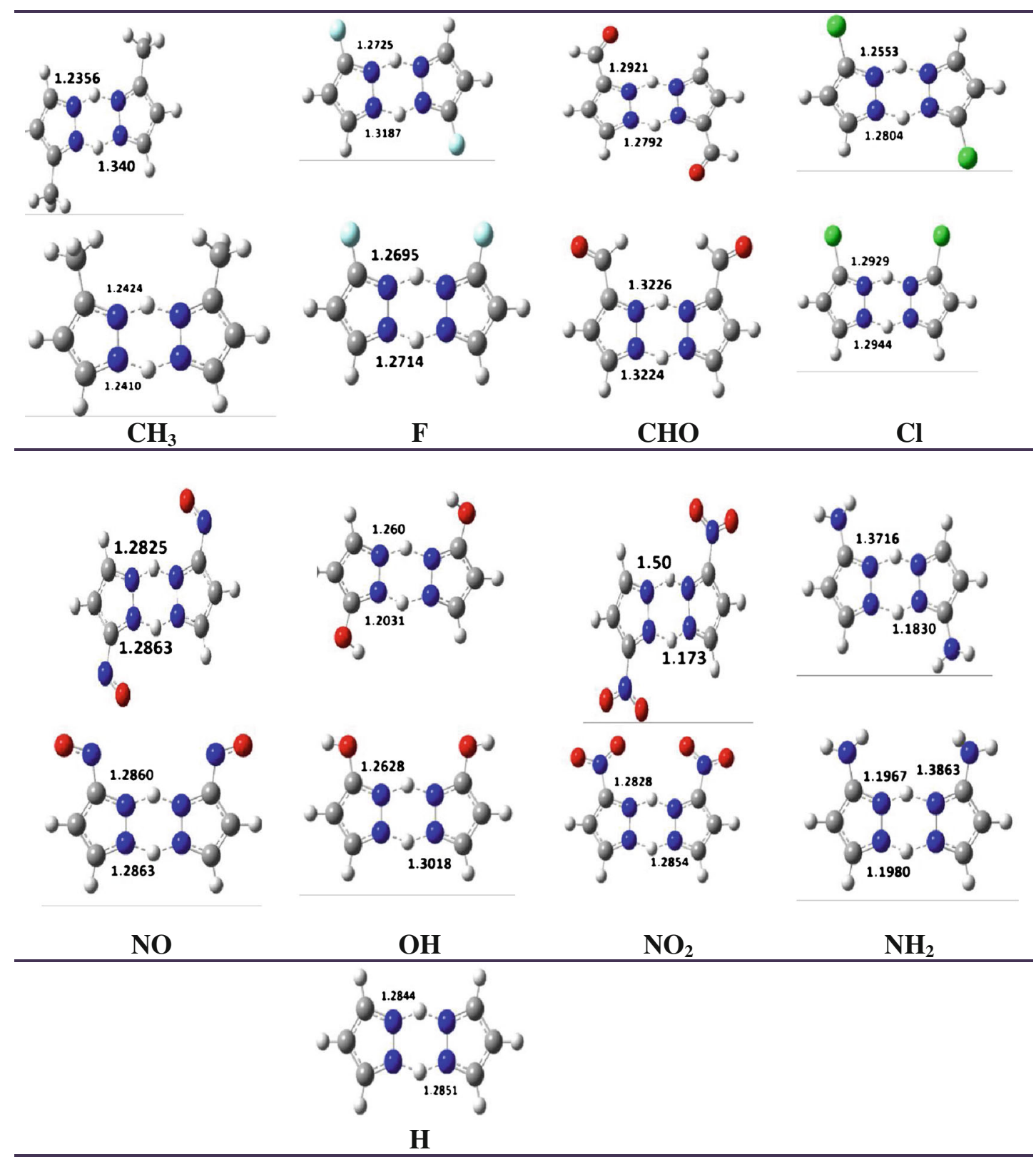

Figure 3. The optimized structures of transition states of hydrogen transfer in the pyrazole dimers calculated at MP2/6-311++G(d,p) level of theory. For each substituent the top structure show the TS of $\mathbf{C} \rightarrow \mathbf{D}$ reaction and bottom show $\mathbf{D} \rightarrow \mathbf{D}$ one.<smiles></smiles><smiles></smiles>

TS1

Figure 4. Schematic diagram of two different transition states of proton transfer reaction assisted by one water molecule. 
Table 4. The calculated activation energies for proton transfer reaction assisted by water or ammonia molecules at MP2/6$311++\mathrm{G}(\mathrm{d}, \mathrm{p})$ level of theory.

\begin{tabular}{|c|c|c|c|c|}
\hline & \multicolumn{2}{|c|}{$\mathrm{H}_{2} \mathrm{O}$} & \multicolumn{2}{|c|}{$\mathbf{N H}_{3}$} \\
\hline & TS1 & TS2 & TS1 & TS2 \\
\hline H & $50.77^{\mathrm{a}}$ & 29.16 & 33.18 & 22.46 \\
\hline $\mathbf{N H}_{2}$ & 48.20 & 28.60 & 32.62 & 21.82 \\
\hline $\mathbf{O H}$ & 49.31 & 28.44 & 31.37 & 20.89 \\
\hline Cl & 48.97 & 27.50 & 28.88 & 19.21 \\
\hline $\mathbf{F}$ & 37.38 & 26.62 & 28.06 & 18.24 \\
\hline $\mathbf{C H}_{3}$ & 50.54 & 29.36 & 33.65 & 22.79 \\
\hline $\mathbf{N O}_{2}$ & 45.37 & 27.73 & 29.31 & 17.25 \\
\hline CHO & 51.13 & 31.78 & 28.0 & 18.68 \\
\hline NO & 47.27 & 28.90 & 25.94 & 18.73 \\
\hline
\end{tabular}

${ }^{\mathrm{a}}$ Activation energies in $\mathrm{kcal} / \mathrm{mol}$.

molecules could influence the whole reaction path by lowering the energy barrier due to the direct participation of protic solvent molecules in the proton transfer process. Selecting the hydrophilic centres on the pyrazole derivatives; we searched the most stable monohydrated and monoammoniated forms for all compounds. With consideration of these structures the proton transfer process assisted by solvent molecules was studied. For this purpose, we have investigated two different mechanisms for the proton transfer reaction assisted by one molecule of water or ammonia. In the first mechanism (TS1), the solvent molecule interacts with proton of pyrazole ring in the transition state where a threemember ring is formed. On the other hand, in the second mechanism, solvent molecule simultaneously take the proton of pyrazole ring from position 1 and give the proton to position 2 through a five member ring. A schematic diagram of two different transition states has been presented in figure 4 .

The results of calculated activation energies for the proton transfer reaction through two different mechanisms assisted by water or ammonia molecules have been shown in table 4 . The results indicate that proton transfer through path 1 needs more energy than path 2. The range of activation energies assisted by water molecule through path 1 was found in the range of $37.38-51.13 \mathrm{kcal} / \mathrm{mol}$ calculated at MP2/6$311++\mathrm{G}(\mathrm{d}, \mathrm{p})$ level of theory. It is worth to note that one can compare these results with activation energies obtained for the proton transfer process of pyrazole derivatives in the absence of solvent molecules that discussed in previous section. As you can see, the activation energies assisted by water molecule decreased for the pyrazole ring substituted by $\mathbf{F}, \mathbf{N O}_{2}$ and $\mathbf{N O}$ groups by $8.41,5.25$ and $4.32 \mathrm{kcal} / \mathrm{mol}$, respectively. However, for the parent pyrazole molecule and substituted pyrazole with $\mathbf{N H}_{2}, \mathbf{O H}, \mathbf{C l}, \mathbf{C H}_{3}$ and $\mathbf{C H O}$ groups activation energy of proton transfer reaction assisted by water molecule increased by $2.51,0.86,1.78,1.66,3.04$, and $0.29 \mathrm{kcal} / \mathrm{mol}$, respectively. Interestingly, when water simultaneously acts as a proton donor/acceptor the activation energies decreased significantly. As noted in table 4 for the parent pyrazole molecule proton transfer through path 2 needs only $29.16 \mathrm{kcal} / \mathrm{mol}$ energy for passing transition state. Similar results were observed for other pyrazole derivatives.

For more precision of effect of explicit solvent molecules, we have investigated the proton transfer reaction assisted by ammonia molecule. As it can be seen, the range of activation energies through path 1 was found to be $25.94-33.65 \mathrm{kcal} / \mathrm{mol}$. The results of activation energies gathered in table 4 reveal ammonia molecule can reduce activation energies more effectively than water. For example, $\mathrm{E}_{a}$ of forward $\mathbf{A} \rightarrow \mathbf{B}$ reaction of parent pyrazole molecule in the presence of water and ammonia molecules are 50.77 and $33.18 \mathrm{kcal} / \mathrm{mol}$, respectively. In addition, similar results obtained when reaction assisted by ammonia molecule through path 2: the activation energies are lower than those found for mechanism 1 . The range of activation energies was found to be $17.25-22.79 \mathrm{kcal} / \mathrm{mol}$.

Water or ammonia molecules through two effects including (a) ring size increasing and (b) increasing the number of hydrogen displacement steps may assist the proton transfer reactions. Through first effect, 4membered ring of free molecule, in the presence of one solvent molecule expands to a 6-membered ring that results in increasing rate of tautomerism.

\section{Conclusions}

MP2 and DFT-B3LYP calculations using 6$311++\mathrm{G}(\mathrm{d}, \mathrm{p})$ basis set were performed to investigate the proton transfer reaction of a series of substituted pyrazoles at 3 or 5 positions. The main results of the 
present study can be summarized in the following manner:

1. The results indicate that for electron donating groups (such as $\mathbf{N H}_{2}, \mathbf{C H}_{3}$, and $\mathbf{F}$ ) 3-substituted pyrazoles (B forms) are more stable but for electron withdrawing groups 5-substituted ones (A forms) are more stable.

2. The results show that activation energies for proton transfer reaction varies in the range of $45.7-$ 51.59 and $49.4-53.96 \mathrm{kcal} / \mathrm{mol}$ at B3LYP and MP2 levels, respectively. Analysis of the results indicates proton migration is easier in pyrazoles with electron donating groups.

3. It was concluded that for 3-substituted pyrazoles, more effective hydrogen bonds are formed for the electron withdrawing groups but for the 5substituted ones, electron donating groups formed stronger hydrogen bonds.

4. Double proton transfer reaction between pyrazole dimers was investigated and moderate activation energies were observed.

5. Proton transfer reaction, assisted by water or ammonia via two different pathways, was investigated and it was clarified that the reaction proceeding through path 2 is more straightforward.

6. Finally, one can compare the simplicity of proton transfer reaction through various studied mechanisms as follows: double proton transfer reaction $>\mathrm{NH}_{3}$-assisted via path $2>$ water assisted via path $2>\mathrm{NH} 3$ assisted via path $1>$ water assisted via path $1>$ single proton transfer reaction.

\section{Acknowledgement}

We thank Isfahan University of Technology (IUT) for the financial support (Through Research Council Grant).

\section{References}

1. Butler R N 1996 In: Comprehensive heterocyclic chemistry (eds.) A R R Katritzky and E F V Scriven (Pergamon) Vol. 5

2. Mukherjee A and Sarkar A 2004 Tetrahedron Lett. 45 9525

3. Rzepecki P, Wehner M, Molt O, Zadmard R, Harms K and Schrader T 2003 Synthesis 1815

4. Kopp K, Lancelot J, Dallemagne P and Rault S $2001 \mathrm{~J}$. Heterocyclic Chem. 381045

5. Francisco M E Y, Seltzman H H, Gilliam A F, Mitchell R A, Rider S L, Pertwee R G, Stevenson L A and Thomas B F 2002 J. Med. Chem. 452708
6. Rinaldi-Carmona M, Barth F, Héaulme M, Shire D, Calandra B, Congy C, Martinez S, Maruani J, Neliat G, Caput D, Ferrara P, Soubri P and Breliere J C 1994 FEBS Lett. 350240

7. Al-Sanea M M, El-deeb I M and Lee S H 2013 Bull. Korean Chem. Soc. $\mathbf{3 4} 437$

8. Ferri N, Bernini S K, Corsini A, Clerici F, Erba E, Stragliotto S and Contini A 2013 Med. Chem. Commun. 4537

9. Llamas-Saiz A L, Foces-Foces C, Mo O, Yanez M, Elguero E and Elguero J 1995 J. Comput. Chem. 16263

10. Llamas-Saiz A L, Foces-Foces C and Elguero J $1994 \mathrm{~J}$. Mol. Struct. 319231

11. Minkin V I, Garnovskii A D, Elguero J, Katritzky A R and Denisko O V 2000 Adv. Heterocycl. Chem. 76157

12. Infantes L and Motherwell S 2004 Struct. Chem. 15 173

13. Stride $\mathbf{J}$ A, Jayasooriya U A, Zanotti J-M and Kahn R 2006 New J. Chem. 30425

14. Klein O, Aguilar-Parrilla F, Lopez J M, Jagerovic N, Elguero J and Limbach H-H $2004 \mathrm{~J}$. Am. Chem. Soc. 126 11718

15. Castaneda J P, Denisov G S, Kucherov S Y, Schreiber V M and Shurukhina A V 2003 J. Mol. Struct. 66025

16. Schweiger S, Hartke B and Rauhut G 2005 Phys. Chem. Chem. Phys. 7493

17. Foces-Foces C, Echevarría A, Jagerovic N, Alkorta I, Elguero J, Langer U, Klein O, Minguet-Bonvehí M and Limbach H H 2001 J. Am. Chem. Soc. 1237898

18. Rzepecki P, Hochdörffer K, Schaller T, Zienau J, Harms K, Ochsenfeld C, Xie X and Schrader T 2008 J. Am. Chem. Soc. 130586

19. García M Á, Cabildo P, Claramunt R M, Pinilla E, Rosario Torres, M, Alkorta I and Elguero J 2010 Inorg. Chim. Acta 3631332

20. Chermahini A N, Teimouri A, Salimi Beni A and Dordahan F 2013 Comput. Theor. Chem. 100867

21. Chermahini A N, Ghaedi A, Teimouri A, Momenbeik F and Dabbagh H A 2008 J. Mol. Struct. THEOCHEM 86778

22. Chermahini A N, Nasr-Esfahani M, Dalirnasab Z, Dabbagh H A and Teimouri A 2007 J. Mol. Struct. THEOCHEM 8207

23. Dabbagh H A, Rasti E and Chermahini A N $2010 \mathrm{~J}$. Mol. Struct. THEOCHEM 94792

24. Chermahini A N, Dabbagh H A and Teimouri A $2007 \mathrm{~J}$. Mol. Struct. THEOCHEM $\mathbf{8 2 2} 33$

25. Frisch M J, Trucks G W, Schlegel H B, Scuseria G E, Robb M A, Cheeseman J R, Zakrzewski V G, Montgomery J A, Stratmann R E, Burant J C, Dapprich S, Millam J M, Daniels A D, Kudin K N, Strain M C, Farkas O, Tomasi J, Barone V, Cossi M, Cammi R, Mennucci B, Pomelli C, Adamo C, Clifford S, Ochterski J, Petersson G A, Ayala P Y, Cui Q, Morokuma K, Malick D K, Rabuck A D, Raghavachari K, Foresman J B, Cioslowski J, Ortiz J V, Baboul A G, Stefanov B B, Liu G, Liashenko A, Piskorz P, Komaromi I, Gomperts R, Martin R L, Fox D J, Keith T, Al-Laham M A, Peng C Y, Nanayakkara A, Gonzalez C, Challacombe M, Gill P M W, Johnson B, Chen W, Wong M W, Andres J L, Gonzalez C, Head Gordon M, Replogle E S and Pople J A 2003 GAUSSIAN 03, Revision B.02 (Pittsburgh PA: Gaussian Inc.) 
26. Lee C, Yang W and Parr R G 1988 Phys. Rev. B 37785

27. Becke A D 1993 J. Chem. Phys. 985648

28. Hatzipanayioti D, Tzeferakos G and Petropouleas P 2008 Chem. Phys. 345119

29. Rospenk M and Koll A 2007 J. Mol. Struct. 844232

30. Boys S F and Bernardi F 1970 Mol. Phys. 19553

31. Foresman J B and Frisch M J F 1996 Exploring chemistry with electronic structure methods (Pittsburgh, PA, Gaussian, Inc)

32. Hehre W J, Radon L, Schleyer P v R and Pople J A 1986 Ab initio molecular orbital theory (New York, Wiley)

33. Parr R G and Yang W 1994 Density-functional theory of atoms and molecules (Oxford University Press)

34. Clark T, Chandrasekhar J, Spitznagel G W and Schleyer P v R 1983 J. Compu. Chem. 4294

35. Shchavlev A E, Pankratov A N and Shalabay A V 2005 J. Phys. Chem. A $\mathbf{1 0 9} 4137$

36. Waluk J 2000 Conformational analysis of molecules in excited states (Weinheim, Wiley-VCH)
37. Elsaesser T and Bakker H J 2002 Ultrafast hydrogen bonding dynamics and proton transfer processes in the condensed phase (Heidelberg, Springer)

38. Tanner C, Manca C and Leutwyler S 2003 Science 302 1736

39. Huynh M H V and Meyer T J 2007 Chem. Rev. 1075004

40. Fang C, Frontiera R R, Tran R and Mathies R A 2009 Nature 462200

41. Tolbert L M and Solntsev K M 2002 Acc. Chem. Res. 35 19-27

42. Hosoi H, Mizuno H, Miyawaki A and Tahara T $2006 \mathrm{~J}$. Phys. Chem. B $\mathbf{1 1 0} 22853$

43. Hammes-Schiffer S 2006 Acc. Chem. Res. 3993

44. Wu D and Jia D 2011 Int. J. Quant. Chem. 111 3017-23

45. Markova N, Enchev V and Timtcheva I 2005 J. Phys. Chem. A 1091981

46. Kyrychenko A and Waluk J E 2006 J. Phys. Chem. A 11011958

47. Chahkandi B, Tayyari S F, Bakhshaei M and Chahkandi M 2013 J. Mol. Graph. Model. 44120 